Supporting Information

\title{
Structural Transition with a Sharp Change in the Electrical Resistivity and Spin-Orbit Mott Insulating State in a Rhenium Oxide, $\mathrm{Sr}_{3} \mathrm{Re}_{2} \mathrm{O}_{9}$
}

Daisuke Urushihara $^{1, *}$, Toru Asaka ${ }^{1,2}$, Koichiro Fukuda ${ }^{1}$, Masanobu Nakayama ${ }^{1-4}$, Yuki Nakahira $^{5}$, Chikako Moriyoshi ${ }^{6}$, Yoshihiro Kuroiwa ${ }^{6}$, Ola K. Forslund ${ }^{7}$, Nami Matsubara ${ }^{7}$, Martin Månsson ${ }^{7}$, Konstantinos Papadopoulos ${ }^{8}$, Yasmine Sassa ${ }^{8}$, Kazuki Ohishi ${ }^{9}$, Jun Sugiyama $^{9}$, Yoshitaka Matsushita ${ }^{10}$, and Hiroya Sakurai ${ }^{11, \dagger}$

${ }^{1}$ Division of Advanced Ceramics, Nagoya Institute of Technology, Nagoya, Aichi 4668555, Japan

${ }^{2}$ Frontier Research Institute for Materials Science, Nagoya Institute of Technology, Nagoya, Aichi 466-8555, Japan

${ }^{3} \mathrm{MaDiS/CMi2,} \mathrm{National} \mathrm{Institute} \mathrm{for} \mathrm{Materials} \mathrm{Science,} \mathrm{Sengen,} \mathrm{Tsukuba,} \mathrm{Ibaraki} 305-$ 0047, Japan

${ }^{4}$ Elements Strategy Initiative for Catalysts \& Batteries, Kyoto University, Kyotodaigaku Katsura, Nishikyo-ku, Kyoto 615-8245, Japan

${ }^{5}$ Graduate School of Science, Hiroshima University, Higashihiroshima, Hiroshima 7398526, Japan

${ }^{6}$ Graduate School of Advanced Science and Engineering, Hiroshima University, Higashihiroshima, Hiroshima 739-8526, Japan

${ }^{7}$ Department of Applied Physics, KTH Royal Institute of Technology, SE-106 91 Stockholm, Sweden

${ }^{8}$ Department of Physics, Chalmers University of Technology, SE-412 96 Göteborg, Sweden

${ }^{9}$ Neutron Science and Technology Center, Comprehensive Research Organization for Science and Society (CROSS), Tokai, Ibaraki 319-1106, Japan

${ }^{10}$ Research Network and Facility Services Division, National Institute for Materials Science, Sengen, Tsukuba, Ibaraki 305-0047, Japan

${ }^{11}$ Center for Green Research on Energy and Environmental Materials, National Institute for Materials Science, Namiki, Tsukuba, Ibaraki 305-0044, Japan

*E-mail: urushihara.daisuke@ nitech.ac.jp

†E-mail: sakurai.hiroya@nims.go.jp 


\section{Powder X-ray Diffraction}

Figures $\mathrm{S} 1$ (a) and $\mathrm{S} 2(\mathrm{a})$ depict the powder XRD patterns of $\mathrm{Sr}_{3} \mathrm{Re}_{2} \mathrm{O}_{9}$ and $\mathrm{Ba}_{3} \mathrm{Re}_{2} \mathrm{O}_{9}$. These diffraction patterns are similar; however, $\mathrm{Sr}_{3} \mathrm{Re}_{2} \mathrm{O}_{9}$ is obviously a lower-symmetry structure because some reflections are split. Each pattern could be indexed to the monoclinic and trigonal systems. In both specimens, no impurity phases were observed at the resolution of the powder XRD measurement in comparison with the simulated XRD patterns as shown in Figures S1(b) and S2(b). The simulated pattern of $\mathrm{Sr}_{3} \mathrm{Re}_{2} \mathrm{O}_{9}$ is calculated using the refined crystal structure in this paper, while that of $\mathrm{Ba}_{3} \mathrm{Re}_{2} \mathrm{O}_{9}$ is calculated using the crystal structure refined by Calvo et al. ${ }^{\mathrm{S} 1}$ Differences in the intensities between obtained and simulated patterns in $\mathrm{Ba}_{3} \mathrm{Re}_{2} \mathrm{O}_{9}$ are due to the preferred orientation. Figure $\mathrm{S} 1(\mathrm{c})$ represents the simulated pattern of $\mathrm{Sr}_{7} \mathrm{Re}_{4} \mathrm{O}_{19}$ reported by Bramnik et al. ${ }^{\mathrm{S} 2}$ This pattern is clearly difference from that of $\mathrm{Sr}_{3} \mathrm{Re}_{2} \mathrm{O}_{9}$ especially in the low-angle region. The single-phase polycrystalline materials of $\mathrm{Sr}_{3} \mathrm{Re}_{2} \mathrm{O}_{9}$ were used to measure the electric properties such as electrical resistivity, magnetic susceptibility, and specific heat. 


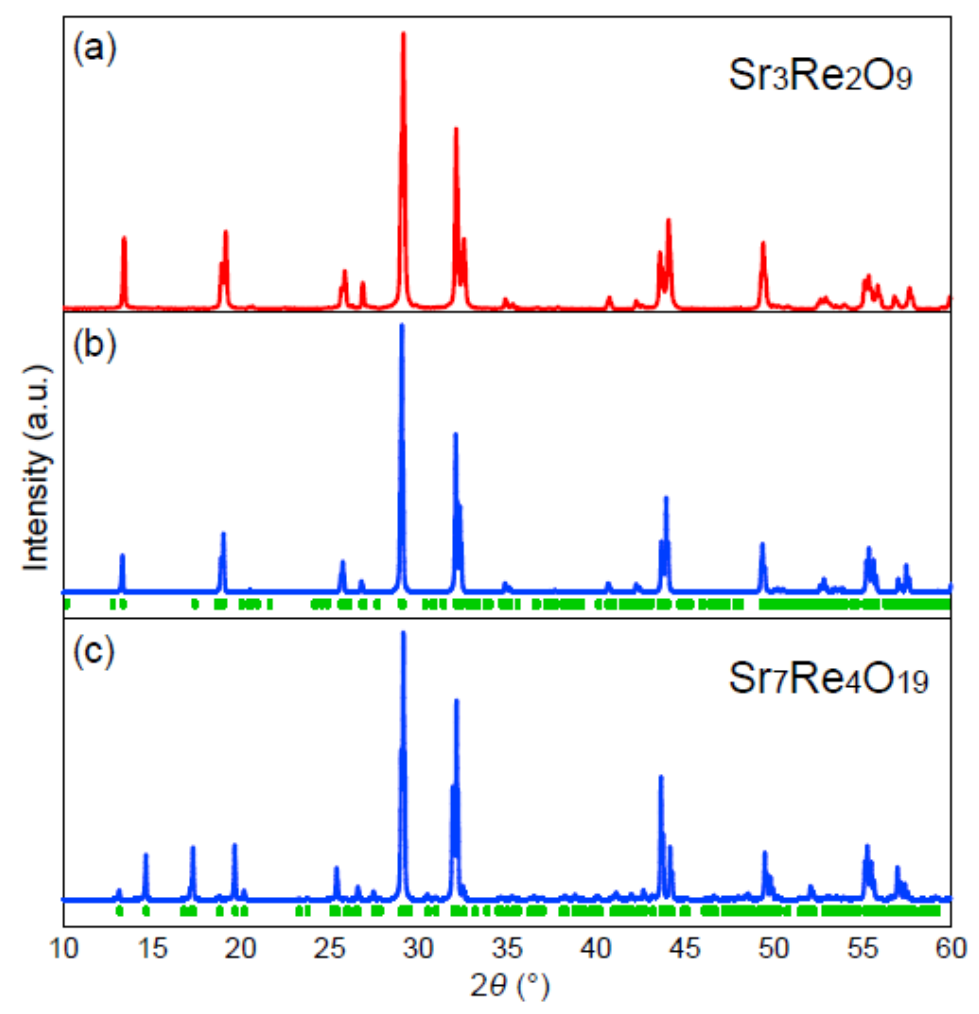

Figure S1. (a)Powder X-ray diffraction pattern and simulated patterns of (b) $\operatorname{Sr}_{3} \operatorname{Re}_{2} \mathrm{O}_{9}$ and (c) $\operatorname{Sr}_{7} \operatorname{Re}_{4} \mathrm{O}_{19}$.

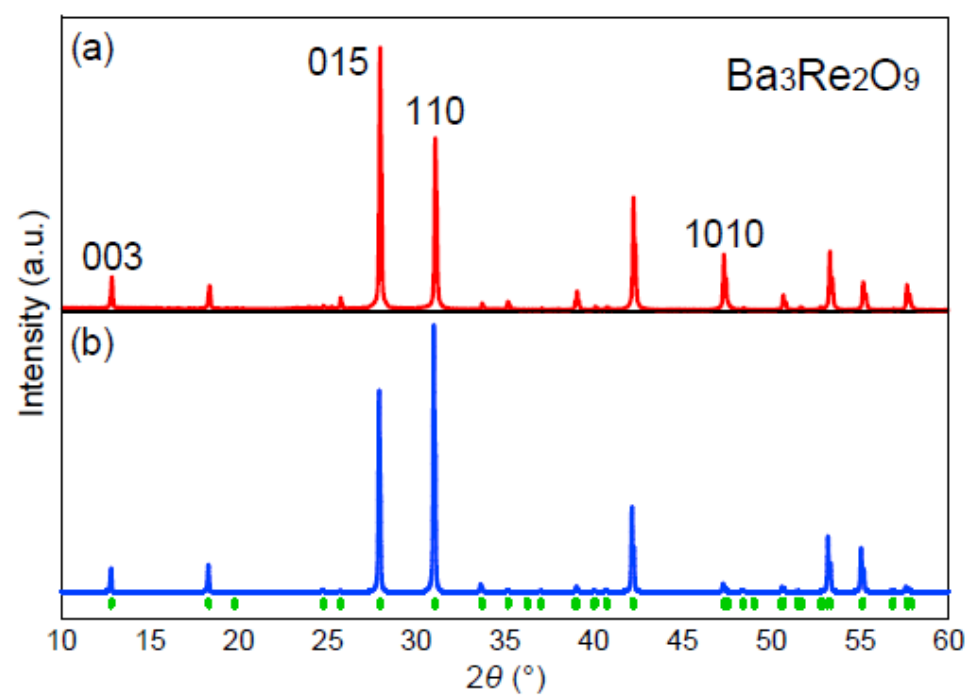

Figure S2. (a)Powder X-ray diffraction pattern and (b)simulated pattern of $\mathrm{Ba}_{3} \mathrm{Re}_{2} \mathrm{O}_{9}$. 


\section{Twin Structure}

Figures S3(a) and S3(b) show the [130] and [110]-zone axis SAED patterns indexed by the LTmonoclinic cell. The diffraction positions of fundamental reflections in Figure S3(a) are in good agreement with those of the [100]-zone axis SAED pattern (Figure 3(a)), which is related by $120^{\circ}$ rotation about the $c^{*}$-axis. In contrast, the superstructure reflections appear in different positions. These patterns suggested that the three-fold symmetry of the HT phase is completely lost in the LT phase. The relationship between the [010] and [110]-zone axis SAED patterns also indicates that the three-fold symmetry was broken.

Figure S3(c) shows the high-resolution single-crystal XRD pattern of $\mathrm{Sr}_{3} \mathrm{Re}_{2} \mathrm{O}_{9}$ obtained using synchrotron radiation at the BL02B1 of SPring-8. ${ }^{\mathrm{S} 3}$ The red, blue, and green markers indicate the reflections of each $120^{\circ}$ twin structure, which appear when the structural phase transition from a trigonal system to a monoclinic system occurs. The ratio of the rotational twin variants in the LT phase was estimated to be $0.635(18): 0.150(14): 0.215(11)$ using single-crystal structure analysis.
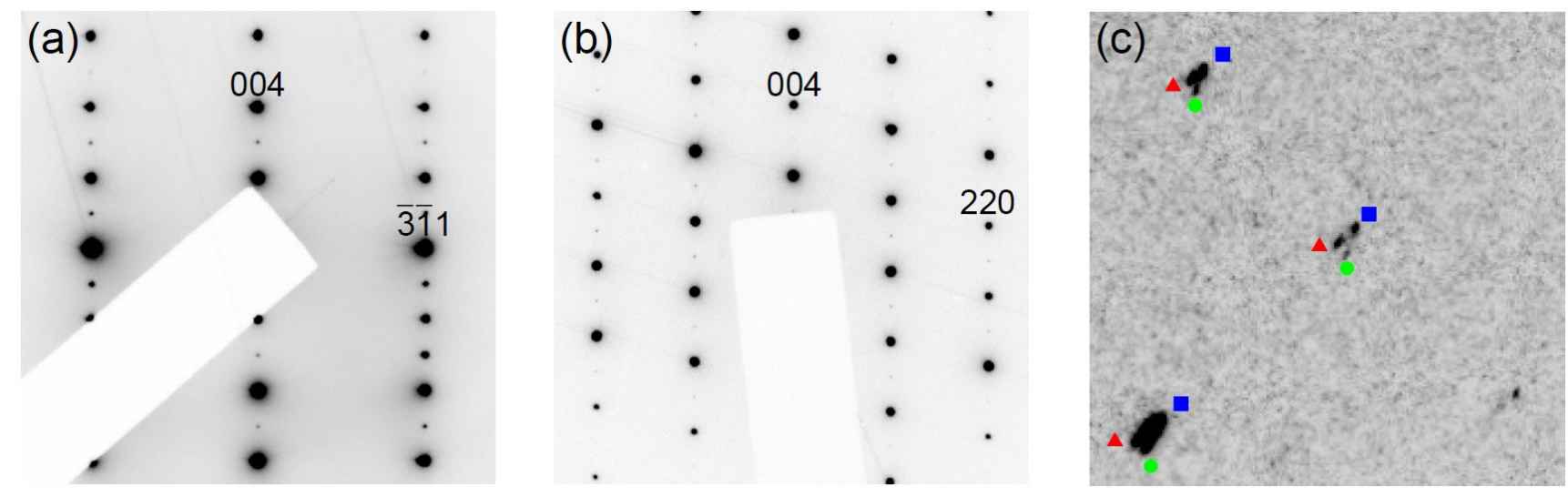

Figure S3. (a) [130]- and (b) [110]-zone axis SAED patterns. (c) Single crystal XRD pattern of $\mathrm{Sr}_{3} \mathrm{Re}_{2} \mathrm{O}_{9}$. 


\section{Temperature dependence of unit cell volume}

Figure S4 shows the temperature dependence of unit cell volume calculated by determined lattice constants. To make comparison between the HT and LT phase, the volume of the LT phase is converted to three fourths. In other words, it corresponds to a volume of $Z=3$. The volume seems to be slightly jumped at the phase transition temperature.

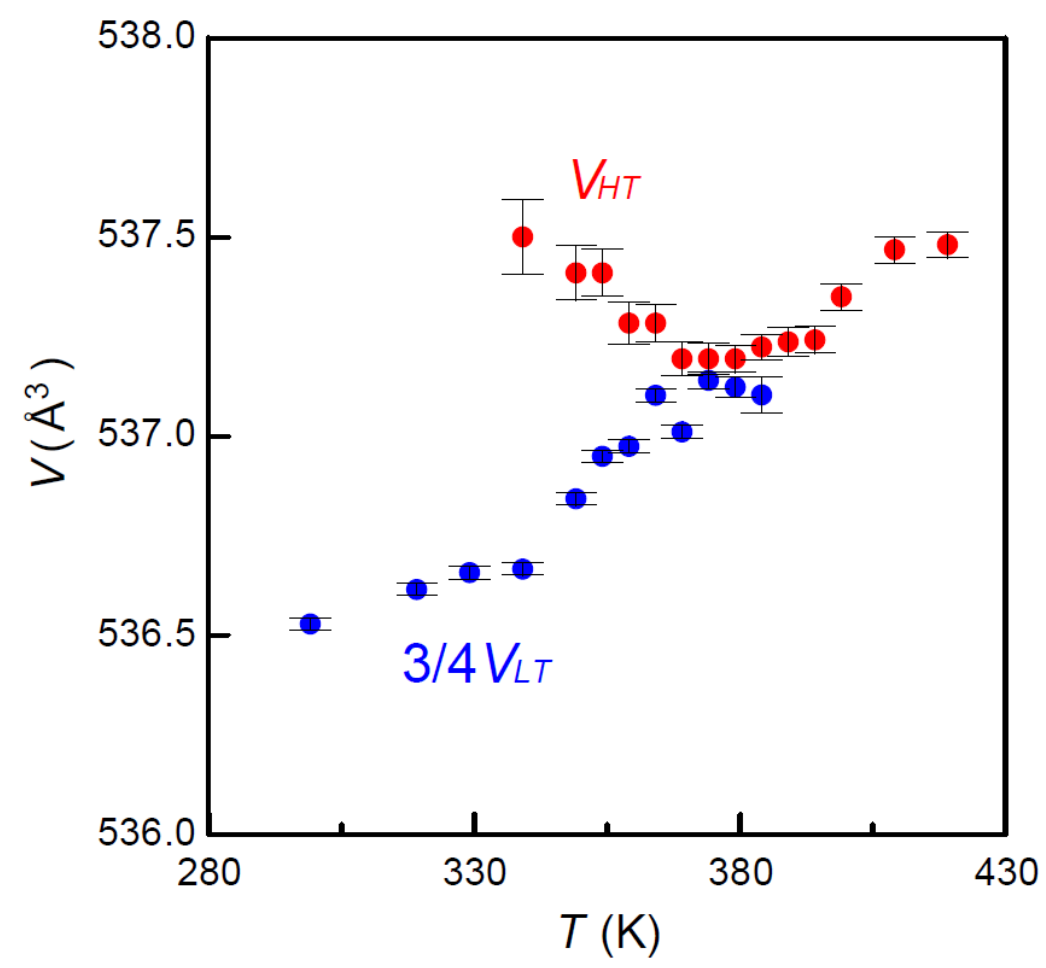

Figure S4. Temperature dependence of unit cell volume of $\mathrm{Sr}_{3} \mathrm{Re}_{2} \mathrm{O}_{9}$. 


\section{Crystal Structure Analysis}

The crystal structures of the LT and the HT phases were refined using the monoclinic $P 2_{1} / n$ and trigonal $R \overline{3} m$ space groups. The initial structural models were determined by the charge-flipping method, which is a structure solution method using alternating modifications in direct and reciprocal spaces. ${ }^{\mathrm{S}}$ The modified initial structure model of the LT phase has fourteen independent sites in the unit cell. The three $\mathrm{Sr}$ sites are $4 e$ sites (Sr1a, Sr1b, Sr2), the two Re sites are $4 e$ (Re1a and Re1b), and the nine $\mathrm{O}$ sites are 4e (O1-9). The HT phase had five independent sites, which had the same Wyckoff positions as those of $\mathrm{Ba}_{3} \mathrm{Re}_{2} \mathrm{O}_{9}{ }^{\mathrm{S} 2}$ Two $\mathrm{Sr}$ sites are at the $3 a(\mathrm{Sr} 1)$ and $6 c(\mathrm{Sr} 2)$ Wyckoff positions, the Re site is a $6 c$ site $(\mathrm{Re} 1)$, and the two $\mathrm{O}$ sites are $9 e(\mathrm{O} 1)$ and $18 h(\mathrm{O} 2)$. The structural parameters and atomic distances are listed in Tables S1-4.

The average bond distances of three $\mathrm{SrO}_{12}$ and two $\mathrm{ReO}_{6}$ polyhedra in the LT phase were $2.737 \AA$, 2.798, and $2.812 \AA$, and 1.935 and $1.931 \AA$, respectively. These values are in good agreement with sum of the effective ion radii: ${ }^{\mathrm{XII}} \mathrm{Sr}^{2+}: 1.44 \AA$, ${ }^{\mathrm{VI}} \mathrm{Re}^{6+}: 0.55 \AA$, and ${ }^{\mathrm{VI}} \mathrm{O}^{2-}: 1.40 \AA^{\mathrm{S} 5}$ In the HT phase, the average bond distances of the two $\mathrm{SrO}_{12}$ and one $\mathrm{ReO}_{6}$ polyhedra were $2.7294 \AA$ and $2.7993 \AA$, and $1.9196 \AA$ A. These values are also appropriate, which suggests that the crystal structure analysis was performed successfully. 
Table S1. Structural parameters and atomic displacement parameters for the LT phase at $298 \mathrm{~K}$ of $\mathrm{Sr}_{3} \mathrm{Re}_{2} \mathrm{O}_{9}$.

\begin{tabular}{lllllll}
\hline \hline Site & $\begin{array}{l}\text { Wyckoff } \\
\text { position }\end{array}$ & $g$ & $x$ & $y$ & $z$ & $U_{\text {eq }}\left(\AA^{2}\right)$ \\
\hline Sr1 & $4 e$ & 1 & $0.00202(11)$ & $0.7556(2)$ & $0.74933(7)$ & $0.0100(4)$ \\
Sr2a & $4 e$ & 1 & $0.0994(2)$ & $0.7492(2)$ & $0.06605(7)$ & $0.0115(4)$ \\
Sr2b & $4 e$ & 1 & $0.10740(13)$ & $0.2461(2)$ & $0.56002(7)$ & $0.0109(4)$ \\
Re1a & $4 e$ & 1 & $0.19689(5)$ & $0.25514(8)$ & $0.84167(3)$ & $0.0060(2)$ \\
Re1b & $4 e$ & 1 & $0.19717(5)$ & $0.75165(8)$ & $0.34028(3)$ & $0.0067(2)$ \\
O1a & $4 e$ & 1 & $0.0004(7)$ & $0.739(2)$ & $0.2462(4)$ & $0.008(2)$ \\
O1b & $4 e$ & 1 & $0.2333(8)$ & $0.4343(13)$ & $0.7320(4)$ & $0.0074(14)$ \\
O1c & $4 e$ & 1 & $0.2478(8)$ & $0.4360(14)$ & $0.2663(5)$ & $0.008(2)$ \\
O2a & $4 e$ & 1 & $0.1135(8)$ & $0.7654(14)$ & $0.5909(5)$ & $0.011(2)$ \\
O2b & $4 e$ & 1 & $0.1145(8)$ & $0.2651(13)$ & $0.0903(5)$ & $0.0062(14)$ \\
O2c & $4 e$ & 1 & $0.1233(8)$ & $0.5263(14)$ & $0.4117(5)$ & $0.012(2)$ \\
O2d & $4 e$ & 1 & $0.1433(8)$ & $0.5276(13)$ & $0.9048(5)$ & $0.009(2)$ \\
O2e & $4 e$ & 1 & $0.1453(8)$ & $0.0281(13)$ & $0.9154(5)$ & $0.009(2)$ \\
O2f & $4 e$ & 1 & $0.1586(8)$ & $0.0202(13)$ & $0.4003(5)$ & $0.008(2)$ \\
\hline \hline
\end{tabular}

\begin{tabular}{lllllll}
\hline \hline Site & $U_{11}$ & $U_{22}$ & $U_{33}$ & $U_{12}$ & $U_{13}$ & $U_{23}$ \\
\hline Sr1 & $0.0087(6)$ & $0.0133(7)$ & $0.0079(3)$ & $-0.0011(4)$ & $0.0018(5)$ & $0.0014(4)$ \\
Sr2a & $0.0103(6)$ & $0.0158(7)$ & $0.0082(4)$ & $0.0002(4)$ & $0.0019(4)$ & $-0.0031(4)$ \\
Sr2b & $0.0104(6)$ & $0.0129(7)$ & $0.0087(4)$ & $0.0017(4)$ & $0.0009(5)$ & $0.0023(4)$ \\
Re1a & $0.0067(3)$ & $0.0073(3)$ & $0.0041(2)$ & $0.0004(2)$ & $0.0013(2)$ & $0.0005(2)$ \\
Re1b & $0.0063(3)$ & $0.0097(3)$ & $0.0041(2)$ & $0.0000(2)$ & $0.0012(2)$ & $-0.0004(2)$ \\
\hline \hline
\end{tabular}

Table S2. Structural parameters and atomic displacement parameters for the HT phase at $420 \mathrm{~K}$ of $\mathrm{Sr}_{3} \mathrm{Re}_{2} \mathrm{O}_{9}$.

\begin{tabular}{lllllll}
\hline \hline Site & $\begin{array}{l}\text { Wyckoff } \\
\text { position }\end{array}$ & $g$ & $x$ & $y$ & $z$ & $U_{\text {eq }}\left(\AA^{2}\right)$ \\
\hline Sr1 & $3 a$ & 1 & 0 & 0 & 0 & $0.0105(2)$ \\
Sr2 & $6 c$ & 1 & 0 & 0 & $0.20970(3)$ & $0.01367(14)$ \\
Re1 & $6 c$ & 1 & 0 & 0 & $0.394483(9)$ & $0.00634(7)$ \\
O1 & $9 e$ & 1 & $1 / 2$ & 0 & 0 & $0.043(2)$ \\
O2 & $18 h$ & 1 & $0.4975(2)$ & $-x$ & $0.22730(11)$ & $0.0169(9)$ \\
\hline
\end{tabular}

\begin{tabular}{lllllll}
\hline \hline Site & $U_{11}$ & $U_{22}$ & $U_{33}$ & $U_{12}$ & $U_{13}$ & $U_{23}$ \\
\hline Sr1 & $0.0104(2)$ & $U_{11}$ & $0.0107(3)$ & $0.5 \times U_{11}$ & 0 & 0 \\
Sr2 & $0.0131(2)$ & $U_{11}$ & $0.0149(2)$ & $0.5 \times U_{11}$ & 0 & 0 \\
Re1 & $0.00633(9)$ & $U_{11}$ & $0.00636(11)$ & $0.5 \times U_{11}$ & 0 & 0 \\
O1 & $0.036(2)$ & $0.061(3)$ & $0.039(2)$ & $0.5 \times U_{11}$ & $0.0204(11)$ & $2 \times U_{13}$ \\
O2 & $0.0229(10)$ & $U_{11}$ & $0.0138(11)$ & $0.0182(11)$ & $0.0012(4)$ & $-U_{13}$ \\
\hline \hline
\end{tabular}


Table S3. Atomic distances ( $\AA$ ) of the LT phase at $298 \mathrm{~K}$ of $\mathrm{Sr}_{3} \mathrm{Re}_{2} \mathrm{O}_{9}$.

\begin{tabular}{|c|c|c|c|c|c|}
\hline Sr1-O1a & $2.739(6)$ & Sr2b-O1a & 3.073(3) & Re1a-O1a & $2.004(6)$ \\
\hline Sr1-O1a & $2.798(6)$ & $\mathrm{Sr} 2 \mathrm{~b}-\mathrm{O} 1 \mathrm{~b}$ & $2.601(3)$ & Re1a-O1b & $1.900(6)$ \\
\hline $\mathrm{Sr} 1-\mathrm{O} 1 \mathrm{~b}$ & $2.913(7)$ & $\mathrm{Sr} 2 \mathrm{~b}-\mathrm{O} 1 \mathrm{~b}$ & $3.378(3)$ & Re1a-O1b & $2.226(6)$ \\
\hline $\mathrm{Sr} 1-\mathrm{O} 1 \mathrm{~b}$ & $2.701(8)$ & $\mathrm{Sr} 2 \mathrm{~b}-\mathrm{O} 2 \mathrm{a}$ & $2.695(3)$ & $\mathrm{Re} 1 \mathrm{a}-\mathrm{O} 2 \mathrm{a}$ & $1.852(7)$ \\
\hline $\mathrm{Sr} 1-\mathrm{O} 1 \mathrm{c}$ & $2.603(8)$ & $\mathrm{Sr} 2 \mathrm{~b}-\mathrm{O} 2 \mathrm{a}$ & $2.902(6)$ & $\mathrm{Re} 1 \mathrm{a}-\mathrm{O} 2 \mathrm{~d}$ & $1.873(6)$ \\
\hline $\mathrm{Sr} 1-\mathrm{O} 1 \mathrm{c}$ & $3.048(7)$ & $\mathrm{Sr} 2 \mathrm{~b}-\mathrm{O} 2 \mathrm{a}$ & $2.602(6)$ & $\mathrm{Re} 1 \mathrm{a}-\mathrm{O} 2 \mathrm{e}$ & $1.757(7)$ \\
\hline $\mathrm{Sr} 1-\mathrm{O} 2 \mathrm{a}$ & $2.641(8)$ & $\mathrm{Sr} 2 \mathrm{~b}-\mathrm{O} 2 \mathrm{c}$ & $2.588(7)$ & $\langle\mathrm{Re} 1 \mathrm{a}-\mathrm{O}\rangle$ & $1.935(6)$ \\
\hline $\mathrm{Sr} 1-\mathrm{O} 2 \mathrm{~b}$ & $2.697(8)$ & $\mathrm{Sr} 2 \mathrm{~b}-\mathrm{O} 2 \mathrm{c}$ & $2.671(8)$ & & \\
\hline $\mathrm{Sr} 1-\mathrm{O} 2 \mathrm{c}$ & $2.740(6)$ & $\mathrm{Sr} 2 \mathrm{~b}-\mathrm{O} 2 \mathrm{~d}$ & $2.639(7)$ & $\mathrm{O} 1 \mathrm{a}-\mathrm{O} 2 \mathrm{a}$ & $3.848(9)$ \\
\hline $\mathrm{Sr} 1-\mathrm{O} 2 \mathrm{~d}$ & $2.574(6)$ & $\mathrm{Sr} 2 \mathrm{~b}-\mathrm{O} 2 \mathrm{e}$ & $2.811(7)$ & $\mathrm{O} 1 \mathrm{~b}-\mathrm{O} 2 \mathrm{~d}$ & $4.099(9)$ \\
\hline $\mathrm{Sr} 1-\mathrm{O} 2 \mathrm{e}$ & $2.809(6)$ & $\mathrm{Sr} 2 \mathrm{~b}-\mathrm{O} 2 \mathrm{f}$ & $2.666(7)$ & $\mathrm{O} 1 \mathrm{~b}-\mathrm{O} 2 \mathrm{e}$ & $3.618(9)$ \\
\hline $\mathrm{Sr} 1-\mathrm{O} 2 \mathrm{f}$ & $2.581(6)$ & $\mathrm{Sr} 2 \mathrm{~b}-\mathrm{O} 2 \mathrm{f}$ & $3.123(8)$ & & \\
\hline \multirow[t]{2}{*}{$\langle\mathrm{Sr} 1-\mathrm{O}\rangle$} & $2.737(7)$ & $\langle\mathrm{Sr} 2 \mathrm{~b}-\mathrm{O}\rangle$ & $2.812(6)$ & Re1b-Ola & $2.035(6)$ \\
\hline & & & & $\mathrm{Re} 1 \mathrm{~b}-\mathrm{O} 1 \mathrm{c}$ & $2.134(6)$ \\
\hline $\mathrm{Sr} 2 \mathrm{a}-\mathrm{O} 1 \mathrm{a}$ & $2.850(6)$ & & & $\mathrm{Re} 1 \mathrm{~b}-\mathrm{O} 1 \mathrm{c}$ & $1.955(7)$ \\
\hline $\mathrm{Sr} 2 \mathrm{a}-\mathrm{O} 1 \mathrm{c}$ & $3.277(6)$ & & & $\mathrm{Re} 1 \mathrm{~b}-\mathrm{O} 2 \mathrm{~b}$ & $1.849(7)$ \\
\hline $\mathrm{Sr} 2 \mathrm{a}-\mathrm{O} 1 \mathrm{c}$ & $2.633(6)$ & & & $\mathrm{Re} 1 \mathrm{~b}-\mathrm{O} 2 \mathrm{c}$ & $1.832(7)$ \\
\hline $\mathrm{Sr} 2 \mathrm{a}-\mathrm{O} 2 \mathrm{~b}$ & $2.700(6)$ & & & $\mathrm{Re} 1 \mathrm{~b}-\mathrm{O} 2 \mathrm{f}$ & $1.779(6)$ \\
\hline $\mathrm{Sr} 2 \mathrm{a}-\mathrm{O} 2 \mathrm{~b}$ & $2.874(6)$ & & & $\langle\operatorname{Re} 1 \mathrm{~b}-\mathrm{O}\rangle$ & $1.931(7)$ \\
\hline $\mathrm{Sr} 2 \mathrm{a}-\mathrm{O} 2 \mathrm{~b}$ & $2.607(7)$ & & & & \\
\hline $\mathrm{Sr} 2 \mathrm{a}-\mathrm{O} 2 \mathrm{c}$ & $3.043(7)$ & & & $\mathrm{O} 1 \mathrm{a}-\mathrm{O} 2 \mathrm{~b}$ & $3.874(9)$ \\
\hline $\mathrm{Sr} 2 \mathrm{a}-\mathrm{O} 2 \mathrm{~d}$ & $2.646(7)$ & & & $\mathrm{O} 1 \mathrm{c}-\mathrm{O} 2 \mathrm{c}$ & $3.752(10)$ \\
\hline $\mathrm{Sr} 2 \mathrm{a}-\mathrm{O} 2 \mathrm{~d}$ & $2.911(8)$ & & & $\mathrm{O} 1 \mathrm{c}-\mathrm{O} 2 \mathrm{f}$ & $3.913(9)$ \\
\hline $\mathrm{Sr} 2 \mathrm{a}-\mathrm{O} 2 \mathrm{e}$ & $2.696(7)$ & & & & \\
\hline $\mathrm{Sr} 2 \mathrm{a}-\mathrm{O} 2 \mathrm{e}$ & $2.735(8)$ & & & & \\
\hline $\mathrm{Sr} 2 \mathrm{a}-\mathrm{O} 2 \mathrm{f}$ & $2.608(7)$ & & & & \\
\hline$\langle\mathrm{Sr} 2 \mathrm{a}-\mathrm{O}\rangle$ & $2.798(7)$ & & & & \\
\hline
\end{tabular}

Table S4. Atomic distances $(\AA)$ of the HT phase at $420 \mathrm{~K}$ of $\mathrm{Sr}_{3} \mathrm{Re}_{2} \mathrm{O}_{9}$.

\begin{tabular}{|c|c|c|c|c|c|}
\hline Sr1-O1 & $2.78380(11)$ & $(\times 6)$ & Re1-O1 & $2.01925(13)$ & $(\times 3)$ \\
\hline $\mathrm{Sr} 1-\mathrm{O} 2$ & $2.675(2)$ & $(\times 6)$ & $\mathrm{Re} 1-\mathrm{O} 2$ & $1.820(2)$ & $(\times 3)$ \\
\hline$\langle\mathrm{Sr} 1-\mathrm{O}\rangle$ & $2.7294(11)$ & & $\langle\operatorname{Re} 1-\mathrm{O}\rangle$ & $1.9196(11)$ & \\
\hline $\mathrm{Sr} 2-\mathrm{O} 1$ & $2.9481(5)$ & $(\times 3)$ & $\mathrm{O} 1-\mathrm{O} 2$ & $3.830(2)$ & $(\times 3)$ \\
\hline $\mathrm{Sr} 2-\mathrm{O} 2$ & $2.8060(14)$ & $(\times 6)$ & & & \\
\hline $\mathrm{Sr} 2-\mathrm{O} 2$ & $2.637(2)$ & $(\times 3)$ & & & \\
\hline$\langle\mathrm{Sr} 2-\mathrm{O}\rangle$ & 2.7993(13) & & & & \\
\hline
\end{tabular}




\section{Sample dependence of magnetic susceptibility}

Figures $\mathrm{S} 5(\mathrm{a})$ and (b) represent the magnet susceptibility of $\mathrm{Sr}_{3} \mathrm{Re}_{2} \mathrm{O}_{9}$ in several samples. Fitting parameters are in good agreement with each other.
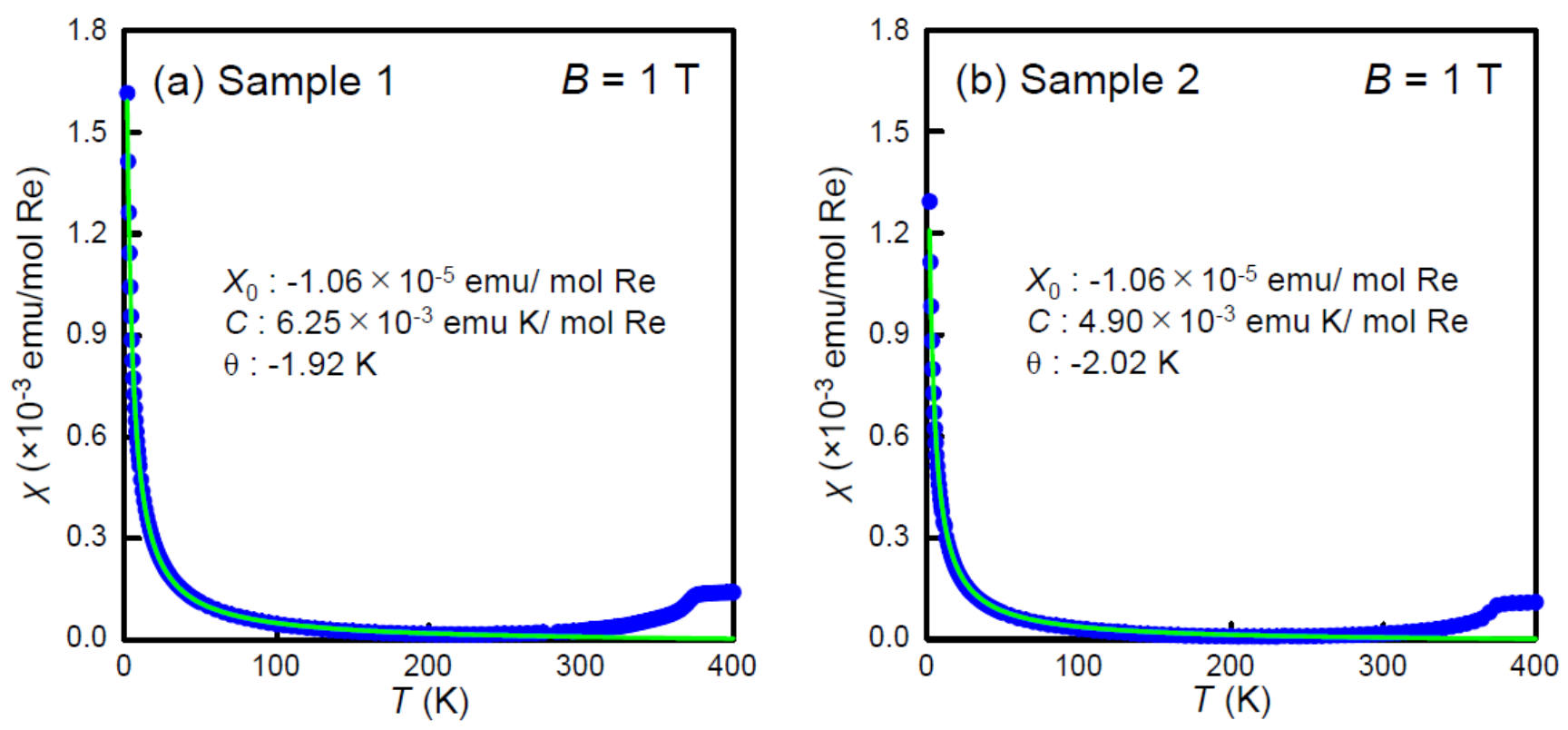

Figure S5. Sample dependence of magnetic susceptibility of $\mathrm{Sr}_{3} \mathrm{Re}_{2} \mathrm{O}_{9}$. 


\section{REFERENCES}

(S1) Calvo, C.; Ng, H. N.; Chamberland, B. L. Preparation and Structure of a Ternary Oxide of Barium and Rhenium, $\mathrm{Ba}_{3} \mathrm{Re}_{2-x} \mathrm{O}_{9}$. Inorg. Chem. 1978, 17, 699-701.

(S2) Bramnik, K. G.; Ehrenberg, H.; Fuess, H. Preparation, Crystal Structure, and Magnetic Studies of a New $\mathrm{Sr}_{7} \mathrm{Re}_{4} \mathrm{O}_{19}$ Double Oxide and its Relation to the Structure of $\mathrm{Ba}_{7} \mathrm{Ir}_{6} \mathrm{O}_{19}$. J. Solid State Chem. 2001, $160,45-49$.

(S3) Sugimoto, K.; Ohsumi, H.; Aoyagi, S.; Nishibori, E.; Moriyoshi, C.; Kuroiwa, Y.; Sawa, H.; Takata, M. Extremely High Resolution Single Crystal Diffractometory for Orbital Resolution Using High Energy Synchrotron Radiation at SPring-8. AIP Conf. Proc. 2010, 1234, 887-890.

(S4) Oszlányi, G.; Sütő, A. Ab initio Structure Solution by Charge Flipping. Acta Cryst. A 2004, 60, 134-141.

(S5) Shannon, R. D. Revised Effective Ionic Radii and Systematic Studies of Interatomic Distances in Halides and Chalcogenides. Acta Cryst. A 1976, 32, 751-767. 